\title{
UMA VISÃO PESSOAL DO LEGADO DO PROFESSOR HANS STAMMREICH
}

José M. Riveros*,a, (D

aDepartamento de Química Fundamental, Instituto de Química, Universidade de São Paulo, 05508-900 São Paulo - SP, Brasil

Recebido em 21/07/2019; aceito em 21/08/2019; publicado na web em 23/10/2019

\begin{abstract}
A PERSONAL VIEW OF THE LEGACY OF PROFESSOR HANS STAMMREICH. Este trabalho apresenta um breve relato sobre alguns aspectos marcantes da vida do Professor Hans Stammreich. Apresentamos em particular os destaques de sua contribuição à espectroscopia Raman, a contribuição feita ao desenvolvimento da espectroscopia molecular no Brasil, e detalhes de sua vida pessoal. Relatamos também o reconhecimento internacional do seu trabalho pioneiro e o legado que deixou através da criação do Laboratório de Espectroscopia Molecular na Universidade de São Paulo.
\end{abstract}

Keywords: Hans Stammreich; espectroscopia Raman; espectroscopia molecular.

\section{INTRODUÇÃO}

A edição de um número da Química Nova in memoriam do Professor Hans Stammreich nos proporciona uma excelente oportunidade para relatar detalhes de sua vida e realçar a sua contribuição ao desenvolvimento da Espectroscopia Raman e da Espectroscopia Molecular. Esta homenagem é particularmente relevante pela diversidade de aplicações atuais da espectroscopia Raman na Química, seja na sua forma tradicional, ou em formatos mais recentes tais como microscopia Raman, Raman ressonante, e as espectroscopias Raman intensificadas (SERS, PERS, TERS). Essas variações da espectroscopia Raman são hoje utilizadas por diversos grupos de pesquisa no Brasil.

Apesar do autor deste artigo ter interagido diretamente com o Professor Stammreich apenas nos últimos dois anos antes do seu falecimento em março de 1969, conseguiu se familiarizar com aspectos científicos e pessoais dele, graças à grande amizade que mantivemos com a viúva dele, a Da. Charlotte Stammreich, falecida no ano de 2008. Foram através das muitas visitas à casa na Rua dos Tamanás 526, no Alto de Pinheiros, e dos relatos fascinantes da Da. Charlotte que nos permitiram conhecer um pouco mais sobre a vida deles.

A identificação do espalhamento inelástico de luz visível, inicialmente relatada por C. V. Raman em $1928^{1,2}$ e quase simultaneamente por Landsberg e Mandelstam, ${ }^{3}$ foi rapidamente reconhecida como uma descoberta fundamental na física. Como tal, Raman foi contemplado com o Prêmio Nobel de Física em 1930, apenas dois anos após a sua primeira publicação. Em poucos anos, e já na década de 1930, a espectroscopia Raman iria atrair interesse como ferramenta potencial de análise química. ${ }^{4,5}$

O início da espectroscopia Raman coincide, em 1930, com a nomeação do Professor Stammreich para dirigir a seção de Espectroscopia da Technische Hochschule Berlin-Charlottenburg (hoje em dia Technische Universität Berlin, ou TU Berlin), instituição na qual tinha iniciado a sua carreira acadêmica como assistente na seção de Fotoquímica. Corriam os anos dos grandes nomes da Física, a qual se encontrava em grande estado de efervescência e principalmente centrada na Alemanha. Das duas grandes instituições de Berlim, a TU Berlin e da Humboldt-Universität zu Berlin, surgiriam até hoje mais de 60 recipientes do Prêmio Nobel nas áreas das ciências exatas. É de fato impossível entrar atualmente no prédio

*e-mail: jmrnigra@iq.usp.br reconstruído do Instituto de Química da TU Berlin na Straße des 17. Juni, ou no Eugene-Paul-Wigner-Gebaüde do Instituto da Física na Hardenbergstraße. 36, ou na Universidade de Humboldt na Unter den Linden 6, ao lado dos grandes museus de Berlim, sem imaginar a riqueza de talentos reunidos em Berlim e o ambiente no qual se encontrava Stammreich nessa época. Stammreich mantinha, em particular, amizade com Albert Einstein, professor então da antiga academia Königlich-Preußische Akademie der Wissenschaften em Berlim de 1914 a 1933. Foi, também, durante os anos em Berlim que Stammreich conheceu a sua esposa, Charlotte, a qual morava num amplo apartamento no mesmo e elegante bairro de Charlottenburg de Berlim.

Estimulado possivelmente por Einstein e as discussões teóricas sobre processos de dispersão e equações de equilíbrio da radiação eletromagnética, ${ }^{6,7}$ e pelo efeito Raman recentemente descoberto, o Professor Stammreich começou a se interessar pelo desenvolvimento da espectroscopia Raman. Tratava-se de uma técnica experimentalmente difícil pelo fato de a radiação inelástica espalhada ser muito fraca comparada com a radiação incidente espalhada. Esse detalhe iria representar um desafio nos primórdios da espectroscopia Raman que exigia exímios experimentalistas para obtenção de espectros. As primeiras tentativas foram interrompidas abruptamente em abril de 1933 quando Hitler decretou a destituição de todos docentes de origem judaica na Alemanha, e coincidiu com a época que Stammreich se encontrava pronto para se submeter ao processo de Habilitation, degrau importante na carreira acadêmica na Alemanha. Essa demissão arbitrária só seria corrigida muitos anos depois pela República Federal da Alemanha que, entre as muitas obrigações de reparação pela II Guerra Mundial, concedeu-lhe uma pensão.

Armado de uma carta de recomendação de Einstein, que a Da. Charlotte guardava trancada a sete chaves e cuja cópia aparece na internet ${ }^{8}$ emigrou rapidamente para Paris fazendo parte da onda de grandes cientistas da Alemanha que iriam se espalhar por diversos países da Europa e pelos Estados Unidos. ${ }^{9}$ Seguiram-se anos de peregrinação até a sua chegada ao Brasil, já relatada de maneira sucinta anteriormente, ${ }^{10}$ e por outros nesta edição da Química Nova. Três anedotas talvez não sejam bem conhecidas e merecem comentários: a) Em 1936, após alguns meses no Iran, aonde tinha sido convidado para estabelecer um laboratório de pesquisas em Físico-Química, empreendeu uma longa e fascinante viagem de carro para a Rússia aonde tinha sido convidado para palestras. Essa viagem permanecia vívida na memória da Da. Charlotte, considerando especialmente as estradas da época. 
b) De volta a Paris, e até a sua saída em 1940, Stammreich e esposa mantiveram uma vida científica e cultural muita ativa. Conviveram com o mundo de grandes intelectuais da época e cultivaram grande amizade com o escritor Arthur Koestler.

c) Em 1940, e após a ocupação da França pelas tropas da Alemanha, Stammreich e esposa empreenderam viagem de navio para o Brasil. No porto de Casablanca, ele foi impedido de continuar viagem e permaneceu em custódia durante algum tempo enquanto a Da. Charlotte continuou viagem até o Rio de Janeiro. Conforme relato da Da. Charlotte, o professor Stammreich só conseguiu sair de Casablanca após ter convencido a trocar de roupa com um marinheiro, e embarcar no navio com a roupa do marinheiro. No Brasil, Stammreich trabalhou inicialmente numa empresa que fabricava lâmpadas a base de descargas elétricas em vapores metálicos (a Philips ??), assunto sobre o qual ele já tinha experiência e que lhe iria render uma patente. Esse conhecimento lhe seria útil na montagem das lâmpadas de excitação para espectroscopia Raman no laboratório na USP. Já estabelecido em São Paulo, e morando numa pequena casa da Rua Inglaterra, no Jardim Europa, desenvolveu interesse durante alguns anos em corridas de cavalo e chegou a ser proprietário de um cavalo que ganharia várias corridas, entre elas o Grande Prêmio de São Vicente. As fotografias desse evento, assim como as taças conquistadas, faziam parte orgulhosa da coleção na residência da Rua dos Tamanás.

Conheci pessoalmente o Professor Hans Stammreich em 1967. Eu acabava de ter concluído o meu doutorado nos Estados Unidos em 1966 em espectroscopia de micro-ondas, e me encontrava na metade do meu estágio de pós-doutorado (1967). Explorava então possibilidades futuras para continuar uma carreira acadêmica fora dos Estados Unidos por estar impedido de continuar no país com o visto de aluno de intercâmbio. Em decorrência de ter sido bolsista de graduação, pós-graduação e pós-doutorado de organizações governamentais dos Estados Unidos tinha a obrigação de retornar ao Paraguai, ou me dirigir a outro país, por um período de pelo menos 2 anos. Tomei conhecimento de alguns dos trabalhos publicados pelo Professor Stammreich e seus colaboradores (principalmente Oswaldo Sala e Roberto Forneris) em periódicos como o Journal of Chemical Physics e Spectrochimica Acta, que conjuntamente com o Journal of Molecular Spectroscopy, eram considerados, na época, como os periódicos mais conceituados em espectroscopia molecular. Eram trabalhos importantes e robustos de espectroscopia, e responsáveis pelo desenvolvimento de excitação de espectros Raman com lâmpadas de He e com luz vermelha. Stammreich era o único espectroscopista da América do Sul conhecido internacionalmente de acordo com o meu orientador de doutorado e o meu supervisor de pós-doutorado. Stammreich catalisou a minha vinda para a Química da USP em novembro de 1967 através do seu apoio firme e a sua recomendação ao Professor Simão Mathias, Chefe do Departamento de Química na época.

Em 1967, o Laboratório de Espectroscopia Molecular ocupava todo o andar inferior do Bloco 4 do Conjunto das Químicas da Universidade de São Paulo na Cidade Universitária, e ainda um laboratório e 2 salas de escritório do andar superior, uma das quais funcionava como biblioteca do Laboratório. A biblioteca reunia uma coleção bastante completa de livros sobre espectroscopia e de alguns periódicos especializados, prática comum de pesquisadores da época que mantinham assinaturas pessoais de periódicos. O Laboratório contava também com uma oficina eletrônica sob a responsabilidade de Geraldo Ayrosa, que iria prestar uma enorme e inesquecível contribuição a vários grupos de pesquisa do IQ da USP, e uma oficina mecânica a cargo do Ricardo (cujo sobrenome não lembro). Nessa época, o Conjunto das Químicas, cuja construção tinha sido concluída em 1965, já aglutinava, nos seus amplos prédios, "catedráticos", docentes e pesquisadores de Química e Bioquímica oriundos de diversas Unidades da USP. ${ }^{11}$ A incorporação do Laboratório de Espectroscopia Molecular nos prédios da Química iria representar um marco importante para a vida futura do Instituto de Química da USP, e o início de uma tradição que teria repercussão em vários Institutos e Departamentos de Química no Brasil.

O Laboratório de Espectroscopia Molecular, criado formalmente pelo Professor Hans Stammreich em 1945 no velho casarão da Física na Avenida Brigadeiro Luiz Antônio № 874, foi responsável pelas primeiras incursões experimentais na área de Físico-Química Molecular do Brasil. O vínculo inicial com a Física da USP é compreensível, já que a grande maioria dos trabalhos fundamentais de espectroscopia até a década dos anos 50 era desenvolvida principalmente por físicos, tanto na Europa como nos Estados Unidos. O seu contato com o mundo dos físicos e o seu reconhecimento permaneceram por muito tempo após o seu falecimento. Tinha boa amizade com o Prof. Marcello Damy de Souza Santos, um excepcional experimentalista da Física da USP e que viria a ser primeiro Diretor do Instituto de Física da UNICAMP em 1967. Dos anos em Paris, surgiu uma amizade com Guido Beck, físico teórico de grande renome formado na Áustria, colaborador de Heisenberg e Rutherford e exilado também em Paris a partir de 1937. Guido Beck teve passagem pela USP na década de 50, pela Argentina, e retornou ao CBPF no Rio de Janeiro em 1975. Após o retorno ao Brasil, Guido Beck visitava São Paulo com frequência e, junto com o Professor Moysés Nussenzveig, que foi o seu orientado na década de 50, mantinha muito contato com a Da. Charlotte e com frequência relembravam aspectos da vida dos Stammreich. Tive a oportunidade de presenciar uma clara demonstração do prestígio do Stammreich entre os seus colegas europeus da época por ocasião da visita ao Brasil, na década de 80, do Sir Rudolf Peierls. ${ }^{12}$ Peierls tinha sido contemporâneo de Hans Stammreich em Berlim, e tornou-se famoso na Inglaterra em 1940 por ter sido o primeiro físico a demonstrar a viabilidade de uma bomba atômica ser construída por fissão a partir de pequena quantidade de U-235. Ele e a esposa fizeram questão de visitar a Da. Charlotte naquela ocasião. Tive o grande privilégio de participar desse jantar, naquilo que foi uma noite memorável de lembranças da época dourada da física atômica.

Cabe também lembrar que a homenagem prestada na biografia sucinta da referência 10 se baseia numa reunião dos pesquisadores alemães com a Da. Charlotte. Da mesma maneira, em 2006 tive a oportunidade de propiciar o encontro do Professor Helmut Schwarz da Universidade Técnica de Berlim, e atualmente Presidente Honorário da Fundação Humboldt da Alemanha, com a Da. Charlotte pelo interesse em reavivar a memória do Stammreich na TU Berlin.

A migração do laboratório do Professor Stammreich para o Conjunto das Químicas foi indiscutivelmente incentivada pela longa amizade e entusiasmo exuberante do Pawel Krumholz, químico de raríssima habilidade experimental e dono de uma cultura química invejável. ${ }^{13}$ Krumholz se incorporou ao Departamento de Química da antiga FFCL da USP como Professor Colaborador em 1966. Ambos já tinham colaborado na publicação de vários trabalhos pioneiros sobre a estrutura e sobre a natureza da ligação química de carbonilas metálicas ${ }^{14,15}$ e de complexos inorgânicos. ${ }^{16}$ Contudo, uma maior identificação da espectroscopia Raman com a Química da USP só viria acontecer, na prática, anos após o falecimento do Professor Stammreich. A atribuição de frequências vibracionais, o formalismo de transformação de coordenadas para coordenadas normais, o uso das matrizes $\mathrm{F}$ e $\mathrm{G}$, a classificação das vibrações conforme os grupos de simetria e teoria de grupos, dados de polarização do espalhamento Raman, assim como os conceitos dos campos de força de Urey-Bradley usados frequentemente, eram assuntos totalmente não contemplados nas disciplinas da Química até 1970. Esses assuntos já se encontravam amplamente discutidos nos livros clássicos da 
espectroscopia vibracional publicados na década de $50,{ }^{17,18}$ mas havia pouca familiaridade dos alunos da Química com a linguagem matemática e física envolvida. De fato, o grupo do Laboratório no fim da década de 70 era ainda constituído por pesquisadores com formação em Física: o Professor Oswaldo Sala (físico), Yoshio Kawano (físico, em fase de doutoramento), Teresinha Teixeira Sans (física, em fase de doutoramento), e a colaboração do Professor Roberto Forneris e Darwin Bassi, já ligados então ao Departamento de Física do ITA em São José dos Campos. Por outra parte, enquanto a espectroscopia infravermelha já começava a ganhar aparelhos comerciais, p.ex. os Perkin Elmer modelos 12 e 21, ${ }^{19}$ dedicados à identificação de grupos funcionais, a espectroscopia Raman ainda dependia de instrumentos caseiros montados nos próprios laboratórios. Os primeiros aparelhos comerciais Raman iriam surgir apenas na segunda metade dos anos 50 com a introdução de fotomultiplicadoras para detecção do espalhamento Raman.

O ano de 1967 registrou também a vinda da Inglaterra do Dr. Richard Spragg, recentemente doutorado pela Universidade de East Anglia em ressonância magnética nuclear. Richard Spragg veio realizar o seu pós-doutoramento atraído pelos trabalhos do Stammreich. Para grande satisfação do Stammreich, o Spragg demonstrou rapidamente grande capacidade e conseguiu publicar vários trabalhos importantes junto com o Yoshio Kawano. A experiência do Spragg no Brasil acabou sendo muito importante já que acabou se tornando um cientista brilhante na Perkin Elmer da Inglaterra. Também em 1967 chegava do Canadá o Professor Leonard Reeves na qualidade de Professor Visitante. O Professor Reeves iria dirigir durante anos a implantação de um laboratório de pesquisa em ressonância magnética nuclear. O Professor Reeves mencionava sempre a sua profunda admiração pelo que o Stammreich tinha conseguido fazer no Brasil, pela originalidade da instrumentação desenvolvida no laboratório e pela engenhosidade do Stammreich através de sua vida científica e pessoal.

O fim dos anos 60 marcou a chegada do primeiro laser a ser utilizado no espectrômetro Raman em substituição às lâmpadas que vinham sendo utilizadas pelo grupo do Stammreich. A introdução do laser como fonte de excitação Raman pelo brasileiro Sergio Porto no Bell Labs ${ }^{20-22}$ tinha demonstrado a enorme vantagem de se utilizar uma fonte monocromática de alta intensidade. Lamentavelmente, o laser sofreu uma avaria no transporte ao Brasil, e dada a burocracia com importações, essa primeira iniciativa tornou difícil o uso do laser.

O Professor Stammreich era bastante reservado e não muito adepto a pequenas conversações. Era extremamente exigente e rigoroso com o trabalho dos seus colaboradores. Alguns o consideravam até bastante áspero no tratamento de pessoas incompetentes, mas acima de tudo era um grande experimentalista. Lembro de algumas de suas observações críticas em conversas mantidas com ele nos primeiros meses de minha estadia no Brasil, e em particular uma frase que até agora lembro. Dizia ele na época, “... no Brasil as pessoas ainda confundem energia potencial com energia cinética ...”, numa clara alusão àqueles que gostavam de se promover. Stammreich se enquadrava dentro da figura do cientista que não precisava alardear de suas realizações, mas tinha um número invejável de patentes e publicações de primeiríssima linha.

Em 1968, e por iniciativa do Professor Krumholz, foi oferecida uma disciplina de graduação optativa denominada Espectroquímica que eu iria ministrar conjuntamente com o Professor Stammreich, o qual seria responsável pela disciplina. Essa disciplina, na qual foram apresentados diversos aspectos de ligações químicas do ponto de vista de química quântica e de diversos tipos de espectroscopia, contou com apenas 2 alunos de graduação matriculados (o Etelvino Bechara, hoje um cientista brilhante no Brasil que chegou a ser Presidente da SBQ), mas com vários alunos de pós-graduação como ouvintes. Considero até hoje uma grande honra poder ter compartilhado essa disciplina com o Professor Stammreich, e marcou o início da introdução de conceitos quânticos nas disciplinas de graduação de Físico-Química.

Sabendo do interesse do Professor Mathias em medidas de momentos dipolares em mercaptanas e tioéteres, e da existência de algumas peças importadas pelo Professor Eurico de Carvalho Filho após a o seu estágio na Universidade de Duke, Stammreich demonstrava ceticismo sobre a viabilidade de montar um espectrômetro de ondas milimétricas. Embora teria sido uma extensão interessante do Laboratório de Espectroscopia Molecular, concordou com a minha observação de que o horizonte da espectroscopia de micro-ondas, assim como a espectroscopia de ondas milimétricas, era muito muito limitado pela baixa volatilidade de substâncias mais complicadas e pela necessidade de registrar espectros de uma mesma molécula com múltiplas substituições isotópicas a fim de determinar estruturas moleculares confiáveis. De fato, somente nestes últimos 15 anos, e com a introdução de espectroscopia de micro-ondas e ondas milimétricas por transformada de Fourier (especialmente na mova modalidade de varredura rápida de frequência pulsada) acoplada a feixes moleculares, houve um verdadeiro renascimento desse tipo de espectroscopia.

No mesmo ano de 1968 surgiram algumas dúvidas sobre a estrutura do radical ${ }^{\circ} \mathrm{CH}_{3}$. A constante hiperfina de acoplamento obtida a partir de espectros de ressonância de spin eletrônico eram condizentes com uma estrutura planar do radical com simetria $\mathrm{D}_{3 \mathrm{~h}}$. Entretanto, a variação dessa constante com a temperatura e o mesmo tipo de espectro para o ${ }^{\circ} \mathrm{CD}_{3}$ sugeriam uma situação talvez um pouco mais complexa. Essas dúvidas estavam também alimentadas por algumas anomalias observadas no espectro vibracional do radical metila, ${ }^{23}$ e especificamente para as frequências vibracionais obtidas para a vibração fora-do-plano dos radicais com diversos números de deutério e com ${ }^{13} \mathrm{C}$. Conversando longamente com o Professor Stammreich, discutia a possibilidade da vibração ser anarmônica, ou refletir um potencial de duplo mínimo com simetria $\mathrm{C}_{3 \mathrm{v}}$ e cuja barreira estaria abaixo do estado fundamental. Ele escutou pacientemente a ideia de tentar calcular esse efeito usando métodos computacionais, aproveitando os recursos computacionais existentes na USP nessa época. Publicações dos anos 60 demonstravam que cálculos de anarmonicidade usando teoria de perturbação são frequentemente inadequados para este tipo de problemas. Dediquei-me durante uns meses a escrever um código em Fortran que permitia diagonalizar matrizes do Hamiltoniano vibracional, incluindo anarmonicidade, usando como funções bases as funções do oscilador harmônico. A diagonalização de matrizes de dimensões de 20x20, ou maiores, foram suficientes para demonstrar que incluindo um termo significativo de anarmonicidade era possível reproduzir exatamente as frequências observadas experimentalmente. Tendo convencido o Professor Stammreich sobre os resultados, foi-me possível publicar os resultados no ano seguinte. ${ }^{24}$

Stammreich viria a falecer inesperadamente em março de 1969 , e só fiquei sabendo do seu falecimento pouco depois de ter chegado de uma viagem ao exterior. Contudo, permanecemos muito próximos da Da. Charlotte, com almoços frequentes aos domingos ou frequentando pizzarias nos domingos à noite, ou acompanhando às vezes a sua natação no Anhembi Tênis Clube, localizado ao lado do Colégio Santa Cruz. Acompanhamos os seus últimos dias no Hospital Albert Einstein, e a pedido dela ficamos encarregados do enterro ao lado do Professor Stammreich no Cemitério Israelita do Butantã. Se encerrava assim o último contato com o Stammreich.

Da. Charlotte deixou uma longa autobiografia de mais de 10 páginas que foi entregue à meia-irmã vinda de Seattle, USA, para o enterro. A casa da Rua dos Tamanás ficou com a sua antiga empregada e fiel escudeira, Mercedes, conforme testamento lavrado em cartório, e a casa vendida após o devido processo do inventário. Hoje em dia, a casa toda reformada nada lembra da residência dos Stammreich. 
O legado científico do Stammreich talvez poderia ter sido relegado ao esquecimento se não fosse pela extraordinária dedicação do Professor Oswaldo Sala, que com enorme esforço, humildade e capacidade conseguiu tornar o Laboratório de Espectroscopia Molecular num polo de atração para gerações de pós-graduandos do Instituto de Química da USP. Muitos que se formaram nesse laboratório iriam se espalhar por diversos centros do Brasil. O Professor Sala tem o grande mérito não somente de ter mantido a tradição do laboratório como de ter transmitido a ênfase na capacitação experimental e na análise crítica de resultados, como na necessidade de manter um grupo coeso centrado em problemas de interesse comum. O conjunto de docentes que hoje integra o Laboratório de Espectroscopia Molecular reúne competências diversas em espectroscopia Raman e mantém, graças ao exemplo do Professor Sala, a seriedade, ética e capacidade que teriam orgulhado o Professor Stammreich.

\section{REFERÊNCIAS}

1. Raman, C. V.; Krishnan, K. S.; Nature 1928, 121, 501.

2. Raman, C. V.; Nature 1928, 121, 619.

3. Landsberg, G.; Mandelstam, L.; Naturwissenschaften 1928, 16, 557.

4. Long, A. D.; Int. Rev. Phys. Chem. 1988, 7, 317.

5. Hibbens, J. H.; The Raman Effect and its chemical applications, Rheinhold Publishing Corporation: New York, 1939.

6. Einstein, A.; Ehrenfest, P.; Z. Phys. 1923, 19, 301.

7. Smekal, A.; Naturwissenschaften 1923, 11, 873.

8. Ver em http://alberteinstein.info/vufind1/Record/EAR000033842, acessada em setembro 2019.
9. Deichmann, U.; Angew. Chem., Int. Ed. 2002, 41, 1310.

10. Schrader, B.; Otto, A.; Bunsen-Magazin 2000, S. 120.

11. Senise, P.; Origem do Instituto de Química da USP. Reminiscências e comentários, Instituto de Química da USP, São Paulo, 2006.

12. Edwards, S.; Phys. Today 1996, 49, 74.

13. Vichi, E. J. S.; Quim. Nova 1983, 6, 152.

14. Stammreich, H.; Kawai, K.; Tavares, Y.; Krumholz, P.; Behmoiras, J; Bril, E.; J. Chem. Phys. 1960, 32, 1482.

15. Stammreich, H.; Kawai, K.; Sala, O.; Krumholz, P.; J. Chem. Phys. 1961, 35, 2168 .

16. Sone, K.; Stammreich, H.; Krumholz, P.; J. Am. Chem. Soc. 1955, 77, 777.

17. Herzberg, G.; Molecular Spectra and Molecular Structure. Volume II: Infrared and Raman Spectra of Polyatomic Molecules, D. Van Nostrand Company: Princeton, 1945.

18. Wilson, E. B.; Decius, J. C.; Cross, P. C.; Molecular vibrations: the theory of infrared and Raman vibrational spectra, Mc-Graw Hill: New York, 1955.

19. Wilks, Jr, P. A.; Anal. Chem. 1992, 64, 833 A.

20. Porto, S. P. S.; Wood, D. L.; J. Opt. Soc. Am. 1962, 52, 251.

21. Leite, R. C. C.; Moore, R. S.; Porto, S. P. S.; Ripper, J. E.; Phys. Rev. Lett. 1965, 14, 7 .

22. Weber, A.; Porto, S. P. S.; Cheesman, L. E.; Barrett, J. J.; J. Opt. Soc. Am. 1967, 57, 19 .

23. Milligan, D. E.; Jacox, M. E.; J. Chem. Phys. 1967, 47, 5146.

24. Riveros, J. M.; J. Chem. Phys. 1969, 51, 1269.

FAPESP contribuiu para custear a publicação deste artigo. 